\title{
Pengembangan Flashcard Dengan Augmented Reality Android Sebagai Sarana Informasi UMKM Kota Cirebon
}

\author{
Ahmad Rizqi Kurniawan, ${ }^{\square}$ Cecep Kustandi², Kunto Imbar Nursetyo $^{2}$ \\ ${ }^{1}$ Universitas Negeri Jakarta, Jakarta, Indonesia. \\ ${ }^{2}$ Universitas Negeri Jakarta, Jakarta, Indonesia. \\ 3 Universitas Negeri Jakarta, Jakarta, Indonesia. \\ DOI: https://doi.org/10.21009/JPI.021.10
}

\begin{tabular}{l} 
Article History \\
\hline Received : 2019 \\
Accepted : 2019 \\
Published : 2019
\end{tabular}

\section{Keywords}

Pengembangan

Flashcard Augmented

Reality Android;

Usaha Mikro Kecil dan

Menengah; Kota

Cirebon;

\begin{abstract}
Abstrak
Penelitian ini bertujuan untuk mengembangkan Flashcard dan aplikasi Augmented Reality berbasis Android yang dapat saling terintegrasi. Pengembangan ini bertujuan untuk memberikan informasi keanekaragaman Usaha Mikro Kecil dan Menengah kota Cirebon kepada masyarakat Indonesia. Peneliti mengembangkan produk ini menggunakan model pembelajaran Integrated Learning Design Framework. Garis besar teori pada penelitian ini adalah teori pengembangan, teori aplikasi Augmented Reality, dan teori Usaha Mikro Kecil dan Menengah. Tahap pertama adalah analisis, tahap kedua pengembangan, tahap ketiga evaluasi dan implementasi. Hasil dari review para ahli mendapatkan skor rata - rata 3,6 termasuk dalam kategori sangat baik. Pengguna mendapatkan skor rata - rata 3.73 untuk uji coba one to one termasuk dalam kategori sangat baik, dan skor rata - rata 3.62 untuk uji coba small group termasuk dalam kategori sangat baik.
\end{abstract}


Usaha Mikro Kecil dan Menengah (UMKM) cukup penting untuk perekonomian negara. Pada saat Indonesia mengalami krisis ekonomi di tahun 1998, ekonomi di Indonesia dapat bertahan dikarenakan UMKM masih beroperasi seperti biasa.

Setiap daerah di Indonesia mempunyai UMKM, pada provinsi Jawa Barat terdapat 26 Kabupaten/ Kota salah satunya adalah Kota Cirebon. Berdasarkan data Badan Pusat Statistik (BPS) UMKM di kota Cirebon pada tahun 2009 terdapat 9.324 unit usaha dan 99.702 orang. Pada tahun 2012 (2018) terdapat 9.379 unit usaha dan 158.320 tenaga kerja yang terserap. Berdasarkan data tersebut banyaknya tenaga kerja tidak sebanding dengan perkembangan atau banyaknya unit usaha.

Penyebab lambannya pertumbuhan Unit Usaha dikarenakan masih banyaknya masyarakat Indonesia yang belum mengetahui akan keanekaragaman dan kualitas dari UMKM Kota Cirebon. Di kota Cirebon terdapat sektor UMKM yang beraneka ragam. Di antaranya adalah ; Kuliner, Kriya, Fashion, Seni Rupa, Seni Pertunjukan, dan lain sebagainya.

Perkembangan Teknologi Informasi dan Komunikasi (TIK), belakangan ini tumbuh sangat cepat. Oleh karena itu peneliti sebagai salah satu mahasiswa Teknologi Pendidikan harus dapat memanfaatkan perkembangan TIK untuk memfasilitasi masyarakat agar lebih mengenal UMKM kota Cirebon yang akan berdampak secara tidak langsung terhadap peningkatan kinerja dari UMKM kota Cirebon.

Di antara sekian banyak perkembangan TIK terdapat teknologi baru yang disebut dengan nama Augmented Reality (AR). AR adalah penggabungan antar 2 objek (objek realitas dan objek virtual) menjadi satu melalui sebuah perangkat. Dalam pengembangan ini peneliti membutuhkan marker agar AR dapat berjalan maka peneliti akan membuat marker dalam bentuk media Flashcard. Selain dijadikan marker, Flashcard juga dapat digunakan untuk mengenalkan UMKM kota Cirebon kepada masyarakat karena gambar bagian depan dari Flashcard dan bagian belakang terdapat informasi terkait UMKM tersebut.

Teknologi AR dapat di gunakan pada beberapa perangkat di antaranya adalah Android, IOS, Windows, dan lain sebagainya. Berdasarkan lembaga survei online Stat Counter pengguna perangkat Android adalah 90,64\%, pengguna perangkat IOS adalah $5,34 \%$, dan o,19 untuk perangkat Windows per bulan Juli 2019. Dari data tersebut peneliti akan melakukan pengembangan AR berbasis Android karena target masyarakat Indonesia lebih banyak menggunakan perangkat Android dibandingkan yang lain.

Maka berdasarkan permasalahan dan data - data yang terdapat di atas pengembang bermaksud mengembangkan sebuah produk Flashcard dipadukan dengan aplikasi Augmented Reality (AR) berbasis Android, guna menambah daya tarik dan mengenalkan kepada masyarakat Indonesia akan besarnya potensi Usaha Mikro Kecil dan Menengah di kota Cirebon, Jawa Barat. Di mana di pada produk yang akan dikembangkan tersebut terdapat beberapa Flashcard dengan Aplikasi AR berbasis Sistem Operasi Android.

\section{METODE}

Penelitian ini dilakukan untuk menghasilkan produk media Flashcard dengan Augmented Reality berbasis android. Pengembangan menggunakan metode pengembangan Integrated Learning Design Framework (ILDF). Pengembangan ILDF terdiri dari tiga tahapan yaitu; Eksplorasi, Penyusunan, dan Evaluasi. Berikut ini adalah rincian prosedur pengembangan dengan menggunakan model ILDF:

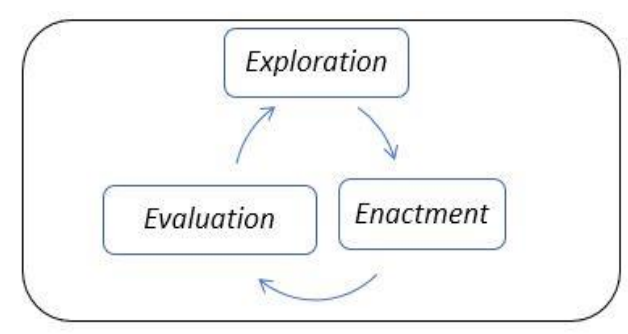

Gambar 1 Model ILDF 


\section{Tahap Eksplorasi}

Pada tahap ini peneliti melakukan eksplorasi, pengembang menggunakan empat tahapan untuk mencapai tahapan eksplorasi yang relevan di antaranya adalah sebagai berikut; Analisis Kebutuhan, Survei Literatur, Pengembangan Teori, dan Analisis Karakteristik Pengguna.

\section{- Analisis Kebutuhan}

Pada tahapan ini peneliti menganalisis latar belakang pengguna yang akan menggunakan media Flashcard dengan Augmented Reality. Sehingga peneliti dapat mengetahui informasi apa saja yang dibutuhkan untuk pengguna.

- Survei Literatur

Tujuan dilakukannya survei literatur ini adalah agar pengembang dapat mengetahui faktor pendukung maupun faktor penghambat yang akan berguna bagi pengembangan produk yang peneliti kembangkan.

- Pengembangan Teori

Pengembang menentukan teori yang dapat memudahkan proses pengembangan media Flashcard dengan Augmented Reality. Pengembang melakukan pencarian teori dimulai dari; teori Flashcard, Augmented Reality, desain pesan, dan teori UMKM. Pengembangan teori tersebut dilakukan agar peneliti mudah dan tepat sasaran dalam mengembangkan produk.

- Analisis Karakteristik Pengguna

Pada bagian terakhir ini pengembang melakukan analisis terhadap sasaran pengguna media Flashcard dengan Augmented Reality. Pengembang menargetkan pada masyarakat umum yang belum mengetahui UMKM kota Cirebon dengan tingkatan pendidikan beraneka ragam serta umur yang beraneka ragam juga. Maka dari itu pengembang akan mencoba mendesain media agar dapat digunakan dengan mudah, interaktif, namun dapat menyampaikan informasi sebaik mungkin.

\section{Tahap Penyusunan}

Pada tahap pelaksanaan ini pengembang melakukan penyusunan sekaligus melaksanakan dari apa yang telah didapatkan pada tahap eksplorasi sebagai bahan pertimbangan. Pada tahap ini terdiri dari 3 sub tahapan yaitu:

- Meneliti dan Mendesain

Pada tahap ini pengembang melakukan penggabungan dan mengoperasionalkan hal apa yang telah dipelajari dan diperoleh pada tahap eksplorasi menjadi sebuah rancangan. Hal tersebut berupa menentukan target pembelajaran (menginformasikan kepada pengguna) dalam inovasi yang dikembangkan (penggunaan media Flashcard dengan Augmented Reality).

- Merancang Bentuk Dasar

Setelah pengembang melakukan penelitian dan mendesain sistem pada tahap ini dapat dilakukan rancangan dasar sebagai rancangan dasar dari media yang akan dibuat (Flashcard dengan Augmented Reality).

- Rincian Lebih Lanjut

Tahap ini adalah tahap perincian dari rancangan dasar, pengembang mulai melakukan perincian lebih lanjut dari rancangan dasar tersebut sehingga mudah untuk dimengerti oleh peserta didik/pengguna. Pengembang mendesain media Flashcard dan Augmented Reality agar pesan yang ingin disampaikan mudah dipahami. 
Ahmad Rizqi Kurniawan | JPI/Vol.o2/No.o1/2019| H. 73-81

\section{Tahap Evaluasi}

Pada tahap evaluasi ini pengembang melakukan penilaian terhadap media Flashcard dan Augmented Reality apakah media tersebut sudah mencapai target dari tujuan awal dari dikembangkannya Flashcard dengan Augmented Reality, Pada tahap evaluasi ini pengembang melakukan empat langkah berikut ini untuk melakukan evaluasi:

\section{- Evaluasi Ahli dan Pengguna} Pengembang melakukan uji coba lalu menggunakan kuesioner yang dibagikan kepada ahli materi, ahli media, dan ahli desain pembelajaran dengan maksud ahli dapat memberikan komentar dan saran agar media Flashcard dan Augmented Reality menjadi mudah dipahami oleh pengguna. Serta melakukan beberapa sampel uji coba penggunaan aplikasi kepada pengguna untuk mendapatkan tanggapan dari pengguna.

\section{- Perbaikan Produk}

Setelah mendapatkan masukan dari ahli desain pembelajaran, ahli materi, ahli media, dan pengguna untuk memperbaiki sesuai dengan saran yang diberi oleh para ahli dan pengguna.

\section{- Implementasi Produk}

Setelah melakukan perbaikan pengembang memulai uji coba kepada pengguna atau masyarakat umum yang ingin mengetahui keanekaragaman Usaha Mikro Kecil dan Menengah kota Cirebon melalui Flashcard dan Aplikasi Augmented Reality. Pada tahap implementasi produk pengembang mendapatkan saran lagi dari pengguna.

Penelitian untuk pengambilan data dilakukan di 10 tempat UMKM Kota Cirebon. Di antaranya adalah; UMKM Pedesan Entog Mas Nana, UMKM Mie Colot, UMKM RM Klapa Manis, UMKM MooCow, UMKM Sinta
Manisan, UMKM Empal Gentong H Apud, UMKM Pondok Kurma, UMKM Bikin Bikin Craft, UMKM Batik Trusmi, dan UMKM Tas Papillon Giva Store. Pengembangan dilakukan selama 9 bulan yaitu Oktober 2018 sampai dengan Juli 2019.

Pada penelitian yang dikembangkan terdapat responden yang menilai dan mengkaji produk yang di kembangkan. Peneliti melibatkan; ahli desain pembelajaran, ahli materi, ahli media, dan pengguna.

Teknik evaluasi yang dilakukan dalam pengembangan Flashcard dan Augmented Reality adalah Teknik evaluasi formatif dilakukan dengan cara uji coba produk kepada ahli, yang terdiri dari; ahli desain pembelajaran (untuk menilai rancangan pembelajaran pada produk Flashcard dan Augmented Reality yang dikembangkan), ahli materi (untuk menilai rancangan materi pada produk Flashcard dan Augmented Reality yang dikembangkan), lalu ahli media (untuk menilai kualitas pada produk Flashcard dan Augmented Reality yang dikembangkan), pengguna dengan teknik one to one dan small group (untuk memberikan saran dari sudut pandang pengguna umum terhadap produk Flashcard dan Augmented Reality yang dikembangkan).

\section{HASIL DAN PEMBAHASAN}

Hasil produk yang dikembangkan pada penelitian ini adalah Flashcard dengan Augmented Reality Berbasis Android Sebagai Sarana Informasi Ekonomi Kreatif dan Usaha Kecil Menengah di Kota Cirebon. Peneliti mengembangkan produk ini dikarenakan terdapat kesenjangan, maka dari itu peneliti mengembangkan produk ini untuk menjadi alternatif mengurangi kesenjangan tersebut. Model pengembangan pembelajaran yang digunakan adalah Integrative Learning Design Frmework (ILDF) yang di mana pada model ILDF terdapat tiga tahapan garis besar; tahap eksplorasi, tahap penyusunan dan pelaksanaan, dan tahap evaluasi. 
Ahmad Rizqi Kurniawan | JPI/Vol.o2/No.01/2019| H. 73-81

\section{Tahap Eksplorasi}

Sebelum mengembangkan suatu produk pengembang melakukan Tahap Eksplorasi yang mencakup dari beberapa tahap di antaranya adalah Tahap Analisis Kebutuhan, Tahap Survei Literatur, dan Pengembangan Teori.

\section{a. Analisis Kebutuhan}

Sebelum mengembangkan sebuah produk pengembang melakukan analisis terlebih dahulu. Dimulai dari mengapa pertumbuhan Usaha Mikro Kecil dan Menengah di kota Cirebon tidak begitu berkembang pesat. Lalu pengembang menganalisis lagi terhadap minat kebanyakan masyarakat di Indonesia. Setelah dilakukan Analisis tersebut pengembang menemukan beberapa hasil di antaranya adalah:

1) Masyarakat Indonesia belum banyak mengetahui Usaha Mikro Kecil dan Menengah di Kota Cirebon.

2) Kurangnya pengenalan Usaha Mikro Kecil dan Menengah di Kota Cirebon kepada masyarakat Indonesia.

Setelah menemukan dua masalah tersebut peneliti mendapatkan solusinya. Peneliti mengembangkan sebuah produk yang dapat digunakan untuk mengenalkan Usaha Mikro Kecil dan Menengah di Kota Cirebon kepada masyarakat.

\section{b. Survei Literatur}

Pada tahap ini peneliti melakukan analisis faktor penghambat dan pendukung yang terdapat pada saat peneliti melakukan pengembangan produk. Berikut ini adalah faktor penghambat dan pendukung yang ditemukan oleh peneliti pada saat melakukan pengembangan produk:
1) Faktor Pendukung

a) Antusiasme pengguna terhadap produk yang dikembangkan oleh peneliti sangat baik

b) Terdapat masukan dari berbagai macam sudut pandang pada saat pengembang melakukan pengembangan produk.

2) Faktor Penghambat

a) Target rentang usia dan latar pendidikan terlalu beragam karena sasaran pengguna adalah masyarakat umum.

b) Terdapat UMKM yang memberikan informasi secara jelas.

c. Pengembangan Teori

Setelah melakukan survei literatur peneliti mencari teori yang dapat mendukung untuk pengembangan media Flashcard dan Aplikasi Augmented Reality berbasis Android ini. Di antaranya adalah sebagai berikut:

1) Teori Media Flashcard

Flashcard adalah media grafis yang berbentuk kartu berukuran sekitar 12 $\mathrm{cm}$ x $8 \mathrm{~cm}$ pada kartu tersebut terdapat gambar, teks, maupun tanda simbol dan disisi lainnya terdapat definisi, keterangan atau uraian maksud dari tampilan sisi lainnya pada kartu tersebut.

2) Teori Augmented Reality

Augmented Reality (AR) adalah sebuah teknologi perpaduan antara objek nyata dan objek virtual. Pada umumnya teknologi AR terdapat objek nyata sebagai acuan lalu pada tampilan virtual terdapat informasi lebih mendalam terkait gambar marker yang terdapat pada Flashcard.

3) Teori Desain Pesan 
Ahmad Rizqi Kurniawan | JPI/Vol.o2/No.01/2019| H. 73-81

Teori desain pesan digunakan untuk menyampaikan pembelajaran sesuai dengan konsep teknologi pendidikan dan pembelajaran pada hakikatnya merupakan kegiatan menyampaikan pesan kepada peserta didik oleh narasumber dengan menggunakan bahan, alat, teknik, dan dalam lingkungan tertentu.

4) Teori Ekonomi Kreatif dan UMKM Pengembang menggunakan Teori Ekonomi Kreatif dan UMKM agar memudahkan peneliti untuk mendapatkan informasi terkait dengan UMKM yang dipilih.

\section{d. Analisis Karakteristik Pengguna}

Peneliti membagi sasaran pengguna menjadi 3 rentang usia (Anak - Anak, Remaja dan Dewasa) dengan latar pendidikan yang beragam. Untuk mengatasi keberagaman latar pendidikan, peneliti memberlakukan minimal kemampuan yang diperlukan untuk menggunakan media, di antaranya:

1) Dapat Membaca

2) Dapat mengoperasikan HP atau Tablet dengan sistem operasi Android

\section{Tahap Penyusunan}

Pada tahap penyusunan ini pengembang melakukan pengembangan produk dimulai dari pembuatan draft (storyboard dan flowchart aplikasi) produk sampai dengan hasil akhir Media Flashcard dengan Augmented Reality.

a. Meneliti dan Mendesain
Pengembang meneliti isi informasi yang akan terdapat pada Flashcard dan Augmented Reality di antaranya adalah:

1) Pengembang meneliti terhadap barang atau jasa apa saja yang banyak diminati oleh masyarakat dari kegiatan sehari hari masyarakat dengan cara peneliti melakukan wawancara langsung terhadap beberapa masyarakat secara acak.

Tabel 1 Hasil Wawancara Minat Masyarakat Sektor UMKM

\begin{tabular}{|l|c|}
\hline \multicolumn{1}{|c|}{ Kategori } & Poin \\
\hline $\begin{array}{l}\text { Aplikasi dan Game } \\
\text { Developer }\end{array}$ & 4 \\
\hline Arsitektur & $\mathbf{2}$ \\
\hline Desain Interior & 17 \\
\hline Fashion & 3 \\
\hline $\begin{array}{l}\text { Film, Animasi, dan } \\
\text { Video }\end{array}$ & 1 \\
\hline Fotografi & 11 \\
\hline Kriya & $\mathbf{2 2}$ \\
\hline Kuliner & 5 \\
\hline Musik & \\
\hline
\end{tabular}

Dari hasil wawancara masyarakat tersebut, disimpulkan terdapat 3 kategori Ekonomi Kreatif dan UMKM yang banyak diminati oleh kebanyakan masyarakat Indonesia. Dari tabel hasil wawancara tersebut disimpulkan minat masyarakat terdapat pada Sektor Kuliner, Sektor Fashion, dan Sektor Kriya.

a) Sektor Kuliner terdapat; Pedesan Entog Mas Nana, Mie Colot, RM Klapa Manis, MooCow Fresh Milk, Manisan Sinta, dan Empal Gentong H Apud.

b) Sektor Fashion terdapat; Batik Trusmi dan Tas Papillon.

c) Sektor Kriya terdapat; Pondok Kurma dan Bikin Bikin Craft.

2) Peneliti memerlukan beberapa informasi Usaha Mikro Kecil dan Menengah di antaranya adalah; 
Deskripsi Usaha Mikro Kecil dan Menengah, Produk atau Jasa yang disediakan oleh Usaha Mikro Kecil dan Menengah, Alamat dan Contact Person yang dapat dihubungi.

3) Pengembang mengambil beberapa gambar/foto berupa contoh barang atau jasa yang disediakan oleh Usaha Mikro Kecil dan Menengah tersebut.

Lalu pengembang menganalisis peralatan yang diperlukan untuk pengembangan produk tersebut di antaranya adalah :

1) Software: Adobe Photoshop, Adobe Illustrator, Microsoft Word, Unity $3 \mathrm{D}$, Visual Studio, Vuforia, dan beberapa software penunjang lainnya.

2) Hardware: Komputer atau Laptop, Kamera, Printer, Kertas, Perangkat Android dan beberapa hardware penunjang lainnya.

\section{b. Merancang Bentuk Dasar}

Pada tahap ini pengembang membuat susunan isi informasi pada Flashcard dan Aplikasi Augmented Reality. Pengembang membuat flowchart alur aplikasi dan storyboard (Kemasan, Petunjuk Penggunaan, Flashcard, dan Aplikasi.

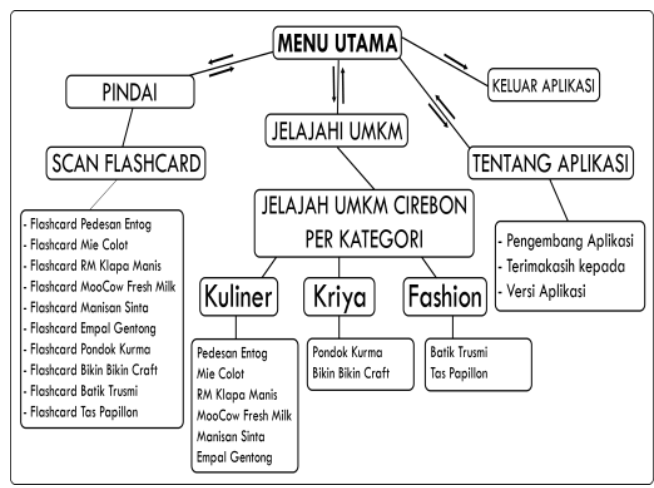

Gambar 1 Flowchart Aplikasi

c. Mengembangkan Produk
Pada tahap ini pengembang melanjutkan rancangan bentuk dasar yang telah dibuat (storyboard), menggunakan komputer dengan software yang telah ditentukan pada tahap meneliti software apa saja yang digunakan.

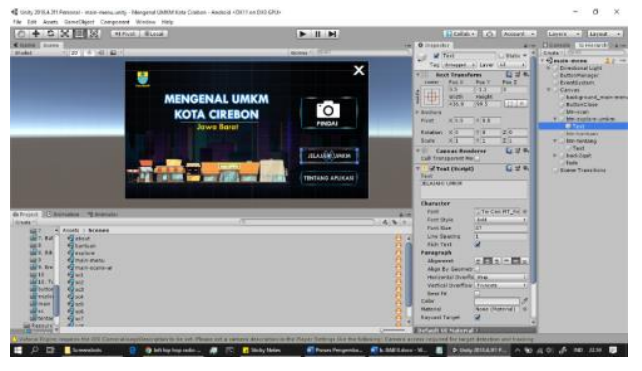

Gambar 2 Proses Pengembangan Produk dengan Unity3D 2018

\section{Tahap Evaluasi}

Pada tahap ini peneliti melakukan beberapa tahap untuk melakukan evaluasi, perbaikan produk dan implementasi produk.

a. Uji Coba Ahli dan Pengguna

1) Uji Coba Ahli

Dari hasil uji coba ahli (desain pembelajaran, materi, media)

Tabel 2 Rekapitulasi Skor Hasil Uji Coba Ahli

\begin{tabular}{|l|r|}
\hline \multicolumn{1}{|c|}{ Responden } & \multicolumn{1}{c|}{$\begin{array}{c}\text { Skor Rata - } \\
\text { Rata }\end{array}$} \\
\hline Ahli Media & 3,65 \\
\hline Ahli Materi & 3,00 \\
\hline $\begin{array}{l}\text { Ahli Desain } \\
\text { Pembelajaran }\end{array}$ & 3,60 \\
\hline \multicolumn{1}{|c|}{ Jumlah } & $\mathbf{1 0 , 2 5}$ \\
\hline \multicolumn{1}{|c|}{ Rata - Rata } & 3,41 \\
\hline
\end{tabular}

Berdasarkan tabel di atas skor rata rata yang diberikan oleh ahli adalah 3,41 yang berarti termasuk dalam kategori "Sangat Baik".

2) Uji Coba Pengguna 
Peneliti melakukan dua kali tahap evaluasi pengguna, yaitu dengan cara perorangan dan kelompok kecil.

Tabel 3 Rekapitulasi Skor Hasil Uji Coba Pengguna Perorangan

\begin{tabular}{|l|r|}
\hline \multicolumn{1}{|c|}{ Nama Responden } & $\begin{array}{l}\text { Skor Rata - } \\
\text { Rata }\end{array}$ \\
\hline Suratmi & 3,8 \\
\hline Putri N & 3,75 \\
\hline Sutijan S.Pd & 3,5 \\
\hline Risa Putri H & 3,7 \\
\hline Nauval Jaya & 3,9 \\
\hline \multicolumn{1}{|c|}{ Jumlah } & 18,65 \\
\hline Rata - Rata & 3,73 \\
\hline
\end{tabular}

Tabel 4 Rekapitulasi Skor Hasil Uji Coba Pengguna kelompok kecil

\begin{tabular}{|c|c|}
\hline Nama Responden & $\begin{array}{c}\text { Skor Rata } \\
\text { - Rata }\end{array}$ \\
\hline Jaya & 3,7 \\
\hline Urip & 3,75 \\
\hline Ratna S & 3,7 \\
\hline Arief Priyono S.Pd. & 3,6 \\
\hline Sulistiyo Wati & 3,5 \\
\hline Alfin M & 3,7 \\
\hline Mulyatin, M.Pd. & 3,6 \\
\hline Pur & 3,5 \\
\hline Zulkifli & 3,5 \\
\hline Frengky S.Pd. & 3,6 \\
\hline Febri Irdian & 3,7 \\
\hline Najib Ali & 3,6 \\
\hline Adam Abdul A & 3,6 \\
\hline Fajar Julianto & 3,6 \\
\hline Raden Erzi S.Sos. & 3,6 \\
\hline Asep Setiono S.Pd. & 3,7 \\
\hline Dewinda N & 3,6 \\
\hline Riska Nimas T & 3,7 \\
\hline Syifa Aulia & 3,6 \\
\hline $\begin{array}{l}\text { Rata - Rata } \\
\text { Keseluruhan }\end{array}$ & 3,6 \\
\hline
\end{tabular}

Berdasarkan tabel di atas skor rata rata yang diberikan oleh pengguna uji coba perorangan adalah 3,73 yang berarti termasuk dalam kategori "Sangat Baik" dan uji coba kelompok kecil 3,62 yang berarti termasuk dalam kategori "Sangat Baik".

\section{b. Perbaikan Produk}

Setelah peneliti mendapatkan komentar dan saran dari ahli materi, ahli media, ahli desain pembelajaran, dan pengguna pengembang melakukan perbaikan sesuai dengan saran yang diberikan dari evaluasi tersebut.

Tabel 5 Komentar dan Masukan

\begin{tabular}{|c|l|}
\hline Ahli & \multicolumn{1}{c|}{\begin{tabular}{c}
\multicolumn{1}{c|}{ Komentar dan } \\
Masukan
\end{tabular}} \\
\hline Media & $\begin{array}{l}\text { - Pemotongan Kertas pada } \\
\text { Petunjuk Penggunaan } \\
\text { agar lebih rapi. }\end{array}$ \\
& $\begin{array}{l}\text { - Flashcard dan Aplikasi } \\
\text { diberi kategori }\end{array}$ \\
\hline \multirow{5}{*}{ Materi } & $\begin{array}{l}\text { - Kualitas kertas kemasan, } \\
\text { petunjuk penggunaan dan } \\
\text { Flashcard di tingkatkan. }\end{array}$ \\
& $\begin{array}{l}\text { - Pemotongan kertas } \\
\text { Kemasan, Petunjuk } \\
\text { Penggunaan, dan } \\
\text { Flashcard di tingkatkan. }\end{array}$ \\
& \begin{tabular}{l} 
- Font di perbagus lagi. \\
\hline
\end{tabular} \\
\hline
\end{tabular}

c. Implementasi Produk

Peneliti melakukan implementasi produk dengan produk yang telah pengembang perbaiki, dengan saran yang telah diberikan oleh para ahli dan pengguna. Dengan cara membagikan tautan unduhan aplikasi Mengenal Usaha Mikro Kecil dan Menengah kepada masyarakat yang berada di sekitar rumah peneliti. Respons yang diberikan oleh masyarakat di beberapa tempat yang peneliti pilih secara acak dan di tempat peneliti melakukan pengembangan mendapatkan umpan 
balik cukup beragam namun lebih berkecenderungan baik.

\section{SIMPULAN}

Penelitian pengembangan ini menghasilkan produk media pembelajaran Flashcard dan Aplikasi Augmented Reality untuk memperkenalkan kepada masyarakat di Indonesia tentang keanekaragaman Ekonomi Kreatif, Usaha Mikro Kecil dan Menengah di Kota Cirebon Jawa Barat. Pada uji coba ahli produk mendapatkan hasil kategori sangat baik, pada uji coba perorangan dan kelompok kecil produk mendapatkan hasil kategori sangat baik. Namun penelitian ini terdapat kekurangan yaitu Terbatasnya Waktu Penelitian di Tempat Usaha Mikro Kecil dan Menengah Kota Cirebon Jawa Barat, dikarenakan peneliti menginginkan data dari UMKM lebih banyak lagi, sedangkan pengembangan produk dilakukan di Jakarta, mengakibatkan peneliti hanya memberikan data atau informasi yang tidak cukup banyak. Lalu penulisan penelitian peneliti masih kurang, dikarenakan waktu peneliti lebih banyak disisihkan untuk pengembangan produk.

\section{UCAPAN TERIMA KASIH}

Alhamdulillah hirobil alamin. Segala puji peneliti ucapkan kepada Allah SWT karena berkatnyalah penulis dapat menyusun artikel jurnal ini. Banyak sekali hambatan dan kendala yang pada saat penulis menulis skripsi ini maupun pada saat pengembangan produk yang dilakukan. Namun berkat do'a dan dukungan baik moril dan materil dari berbagai pihak akhirnya peneliti dapat menyelesaikan artikel ini. Oleh karena itu penenliti mengucapkan terima kasih sebesar besarnya kepada semua pihak yang telah membantu dalam penyusunan skripsi ini, terutama kepada; Bapak Cecep Kustandi, M.Pd., selaku Dosen Pembimbing I dan Bapak Kunto Imbar Nursetyo, M.Pd., selaku Dosen Pembimbing II Skripsi, Bapak Dr. Robinson Situmorang, M.Pd., selaku Dosen yang memberikan referensi penelitian ini. Mas Nana dari Pedesan Entog, Ibu Dwita dari Bikin Bikin Craft. Sinta Manisan, Giva Store, dan semua UMKM yang telah mempersilahkan peneliti mengambil informasi terkait UMKMnya.

\section{DAFTAR PUSTAKA}

Hendri, S. (2015). Teknologi Augmented Reality Berbasis Android Dalam Pembuatan Brosur Interaktif-Integritas Politeknik. Medan: Politeknik Negeri Medan.

Kustandi, Cecep dan Sutjipto, B. (2011). Media Pembelajaran: Manual dan Digital. Bogor: Ghalia Indonesia.

Pengertian Ekonomi Kreatif dan Ciri, Jenis dan Sektor Ekonomi Kreatif (2018, 11. September) Diunduh 11 September 2018 dari Pelajaran.co.id:

https://www.pelajaran.co.id/2018/30/pengert ian-ciri-jenis-dan-sektor-ekonomikreatif.html

Stat Counter. (2019, Agustus 07). Diambil kembali dari Mobile Operating System Market Share in Indonesia - July 2019: http://gs.statcounter.com/os-marketshare/mobile/indonesia 